\title{
Animals, animacy and anthropocentrism
}

\begin{abstract}
This paper explores various ways in which contemporary British English depicts degrees of animacy among nonhuman animals, and demonstrates the anthropocentric qualities of much discourse about animals. The first section reviews discussions of animacy in relevant research literature, highlighting how these often take for granted a categorical distinction between humans and other animals, before demonstrating how both corpus-assisted approaches to discourse analysis and developments in the analysis of animacy point to a more complex picture. The second section discusses the implications of recent work in social theory for understanding organisms, and their degrees of animacy, from the perspective of networks rather than hierarchies. The third section of the paper presents analyses of an electronically stored corpus of language about animals. Three analyses of naming terms, descriptors and verbal patterns associated with various non-human animals illustrate a range of ways in which their animacy is denoted and connoted. They also demonstrate the influence of discourse type and human purpose on depictions of animals and assumptions about their animacy.
\end{abstract}

\section{Introduction}

"It is just like man's vanity and impertinence to call an animal dumb because it is dumb to his dull perceptions."

Mark Twain What is Man?

Human language is a human construct, so it is a truism that when linguists analyse its grammar and vocabulary they inevitably do so anthropocentrically. Notwithstanding recent findings about the capacities for communication of other species, there is no evidence that nonhumans have engaged in the metalinguistic enterprise represented in this journal. Neither do they (as far as we know) speculate as to the possible origins of their respective species or the evolutionary processes by which they have come to be what they are. Such observations give rise to a belief in human exceptionalism. Simultaneously, one of our limitations as human beings - even given the extraordinary affordances of the technology developed by members of our species - is 
that we can only perceive the world from a human perspective, by using the senses available to our species. Humans are, by default, the yardstick or benchmark against which other species are compared. Attempts to challenge this, both ethical and ontological, go back centuries. In 1789, Jeremy Bentham proposed that 'the question' about how animals should be treated was not, Can they reason? nor Can they talk? but Can they suffer? And the question of whether other animals are not so much lacking in human capacities as possessing different ones was raised by Montaigne in the $16^{\text {th }}$ century. Both these issues continue in contemporary debates, which often touch on, but rarely explore in depth, the linguistic means by which animal experiences are encoded in language. How, then, are the modes of perception and action of nonhumans represented in human language? What role does language play in the hierarchical relationships between humans and other animals in terms of their respective degrees of animacy? Although such broad and deep questions are well beyond the scope of this short paper, I begin by sketching some key themes in this area, before introducing the corpus used as data for this study and the approaches I have taken to analysis. The remaining sections detail several explorations of how animals are depicted, with particular reference to the ways they are represented as agents of processes, leading to some conclusions about the challenges presented to conventional linguistic analyses by a topic-specific corpus of texts about non-human animals.

\section{Animacy: hierarchies and taxonomies}

Arguing for animacy as an ontological category, Dahl (2008: 142) defines it as "the capacity for perceiving and acting upon the environment", while the linguistic definition proposed by Folli and Harley (2008: 191) is "the inherent qualities and abilities of the entity to participate in the eventuality denoted by the predicate". Linguistic research into degrees of animacy usually notes a categorical distinction between humans and other animals, finding evidence across languages for that distinction being encoded in their grammars (e.g. Croft, 1991).

Animacy is, for O. Dahl and Fraurud (1996), "at the bottom a question of a distinction between 'persons, that is, essentially human beings perceived as agents, and the rest of the universe"” (cited in O. Dahl, 2008: 145). This "hierarchical scale of animate 
and inanimate beings" is, according to Yamamoto (1999: 9), "a product of anthropocentric human cognition"; (see also Enger \& Nesset, 2011). Humans are invariably represented as situated at the top of the hierarchy or the centre of the circle of animacy and/or empathy (Langacker, 1991). These spatial metaphors - the centre of the circle, the top of the hierarchy - have analogues, at least in Western European traditions, in representations of humans and other organisms in biological taxonomies. The Greek philosophers viewed both the social and natural worlds as gradations from the lowest to the highest (Clutton-Brock, 1995: 427), and I return to the implications of this linguistic-biological parallel below. The medieval belief in a Scale of Nature, or Great Chain of Being, posits a hierarchical scale of both animacy and importance, with non-living matter at the base, through plants and the 'lower' animals, up to the quadrupeds and then 'Man', above whom are found only the angels and God. This hierarchical arrangement, from which 'Man' looks down on other species, persists, but alongside it is an alternative vantage point, with the human at the centre and other organisms ranged around, here graded according to their utility to human beings. Such criteria are found alongside the descriptions of animals' anatomy and behaviour that have been taken into account in taxonomies since Aristotle. Early modern classifications considered animals as edible/inedible, wild/tame and useful/useless (Thomas, 1983: 53), and this kind of approach is still adopted for some purposes. For example, Santamaria, Fallon, Green, Schulz, and Wilcke (2012) have developed an ontology for classifying animals in relation to their "practical uses that are of interest to science, medicine and agriculture", including animals" "production role such as meat or milk for human food" (p.1). However, since first Linnaeus and then Darwin, most biological taxonomies have been based on explicitly objective criteria, consistent with another metaphorical image, "the phylogenetic tree, which, at least in general form and shape, resembles a genealogical tree of a human dynasty" (Tudge, 2000: 3). Whereas the hierarchies presented in contemporary zoology textbooks therefore eschew classification by superficial characteristics such as visual or behavioural similarity, making use instead of information about shared evolutionary history, they nevertheless tend to be organised in sections which echo earlier hierarchies, from the smallest and least complex organisms at the base to the most complex and 'sophisticated' at the apex. 
Classification of the diversity of life-forms has been a consistent concern of zoologists - and of course it has implications for nomenclature and thus for linguistic systems. As (Thomas, 1983: 52) notes, consistently with the cognitive linguists cited above:

... all observation of the natural world involves the use of mental categories with which we, the observers, classify and order ...; and it is notorious that, once these categories have been learned, it is very difficult for us to see the world in any other way.

These mental - and linguistic - categories are also sustained by cultural and political arrangements. While ethologists may be providing ever more evidence of cognition, emotion, and sociality in creatures previously regarded as lacking significant capacities, the implications may be inconvenient for vested interests, such as the meat industry, for example. As Nussbaum (2007: 35) notes, "we need to remember that we are relatively ignorant of what a good life for each sort of animal is and strongly biased in favor of our own power and interests."

\section{Linguistic markers of animacy}

Research into linguistic indicators of animacy has often had the aim of crosslinguistic comparison and the identification of universals. So, understandably, with limited exceptions (see below), fine-grained comparisons between any potential linguistic markers for different categories of non-humans are rarely found in these accounts. Some of the linguistic dimensions identified by previous researchers, such as case marking (e.g. Comrie, 1989; Malchukov, 2008), are less relevant in the context of the present study; similarly, first and second person pronominals rarely feature in relation to animals in our data. A recent project aimed at annotating corpora of contemporary English for animacy (Zaenen et al., 2004) concluded that as a linguistic category it is far from being well understood; furthermore, these authors found too few occurrences of their 'ANIMAL' category in the corpora they used to produce any results. They also point out discrepancies between linguistic and biological definitions of both the animate/non-animate distinction and the human/nonhuman one (see also Atran 1999, De Swart et al. 2008; c.f. Arluke and Sanders, 1996, on the 'sociozoologic scale'). 
Three linguistic markers in particular have received attention, however, in literature that is concerned specifically with how animals are represented in (English) discourse. One of these is the number system, and the tendency for words for commodified animals to be unmarked in the plural (sheep, fish), and/or to function as mass nouns (lamb, chicken, livestock) (e.g. Halliday, [1990] 2001; Stibbe, 2006). Another is the choice of pronouns: who vs. which; he, she vs. it etc. (e.g. Gupta, 2006; Sealey \& Oakley, 2013). And a third is the inclusion in the gender system of some animals and the exclusion of others (e.g. Gilquin \& Jacobs, 2006). While the present study concerns only English, it is interesting that descriptions of various languages note differential applications of the gender system for animals of different kinds (e.g. distinctive genders being accorded to those thought of as 'important or interesting', Leheckovd 2000, or as having some 'social standing', Mosel \& Spriggs 2000). Indeed, Dahl (2000: 100) recognises that, at least in respect of gender, "[i]t is misleading, in most cases, to think of ANIMAL as a single 'step' in the hierarchy". Elsewhere, Dahl (2008: 142) explains that in his view animacy is not reducible to a single hierarchy but rather "tends to interact with a host of other factors, yielding bundles of syntactic, semantic and pragmatic properties that tend to occur together". Similarly, Hopper and Thompson (1994: 357) maintain that grammatical markers of properties such as animacy derive from "the entire range of cognitive, social, and communicative factors involved in the actual use of language".

\section{Humans and other animals as networks}

As the effects of human activity on the planet become increasingly obvious and alarming, the long-established patterns of biological hierarchies are being unsettled by the work of social theorists such as Deleuze, Guattari, Latour, Haraway, Barad, Braidotti, DeLanda and others. Space does not permit more than a very cursory exposition of these ideas, but some of the challenges of post-humanism and the 'new materialisms' (Coole \& Frost, 2010b) that are most relevant to this paper include the following: a breaking down of any absolute distinction between human and other lifeforms; a recognition that "the material realm is irreducible to culture or discourse and that cultural artifacts are not arbitrary vis-à-vis nature" (Coole \& Frost, 2010a: 27); a rejection of reductive individualism in favour of relationality, and of linear causality 
in favour of complex, dynamic, and processual explanations. Also significant, for the current paper, is the reaction against a concern with 'macrobes' at the expense of microbes (Dupré, 2012: 75). As we found in our research, when people are prompted to reflect on 'animals', the kinds that typically come to mind are those that are 'big like us' (Hird, 2009) - vertebrates, sexual reproducers, creatures conventionally thought of as separate, integral beings, susceptible to the kinds of classification summarised above. However, as biologists and philosophers continue to grapple with 'the species problem' (Pavlinov, 2013), they encounter “... the question whether life can indeed be arranged in a tree, or whether we must rather see it as a web or net" (Dupré, 2012: 12), and life-forms as temporary 'assemblages' (Bennett, 2010; Deleuze \& Guattari, 1988; Hird, 2009).

\section{A corpus of texts about animals}

The research project into the discursive representation of animals, on which this paper draws, collected data from a wide range of sources, including many different kinds of texts featuring many different kinds of animal, in order to identify patterns in how contemporary British English speakers refer to nonhuman animals (see Appendix for a list of corpus contents). ${ }^{1}$ By confining our list of animal naming search terms to those for animals visible to the naked (human) eye, we too were guilty of 'macrobocentrism' (Dupré \& O'Malley, 2007: 842), which privileges the conception of every 'animal' as an independent, multicellular individual. As explained elsewhere (Sealey \& Pak, forthcoming in 2018), composing a list of search terms in order to identify relevant texts for the corpus was not a straightforward matter. Nevertheless, this process confirmed that it is mainly as individual entities that our language represents animals and animal kinds to us. (There are additional naming terms for the products derived from animals for consumption, and for categorising animals according to how they feature in human experience, which we discuss elsewhere, but this does not undermine the general point about how English vocabulary itemises living organisms.) Contemporary challenges to these assumptions (of 'macrobocentrism', and of animals as independent, multicellular individuals visible to humans) derive from the acknowledgement of the interaction, within any living organism, of multiple life-forms, leading to "the collapse of the autonomous individual organism in favour of organisms as assemblages" (Hird, 2009: 67), where 
microbes not only 'invade' bodies to cause infection, but co-exist and co-operate with, and indeed are essential for the existence of, the larger bodies where they live. This insight has implications for the identification of degrees of animacy, and the language in which to denote these, as we shall see.

I turn now to the specifics of the naming terms in our corpus of texts about animals. Our corpus contains a range of discourse types, constructed around a search list of over 2000 animal naming terms. As mentioned above, this list did not include terms for micro-organisms, although such words do feature in some of the texts we collected, particularly the academic science journal articles. The questions addressed in the remainder of the paper are the following, in relation to the animals named in the corpus: How are degrees of animacy indicated in the patterns of verbs of which animal naming terms are subjects? How consistent are representations of animacy across different discourse types? To what extent do these patterns accord with the hierarchies recorded in the literature cited above?

\section{Approaches to analysis}

The investigation of degrees of animacy associated with different animals in the texts that comprise our corpus necessitates taking account of a range of linguistic features, discoursal, semantic and grammatical. In the present study, the focus is predominantly on verbs of which animals are subjects or agents, and the approach I have taken is empirical, inductive and iterative. One candidate approach, from Systemic Functional Linguistics, is the transitivity system, which "construes the world of experience into a manageable set of PROCESS TYPES” (Halliday \& Matthiessen, 2004: 170). A potential problem here, as reported in an earlier study (Sealey \& Oakley, 2013) is that of circularity, in that an attribute identified as indicating 'animacy' may be presupposed in the definition. Thus in Halliday's transitivity system, a verb is classified as of the 'mental process' type if it meets the following condition: "there is always one participant [the 'Senser'] who is human ... [or] human-like; the significant feature ... is that of being "endowed with consciousness"” (2004: 201). This raises a question for the classification of verbs of which animals are subjects: does the use of a verb denoting a mental process confer consciousness and thus animacy on to the subject, or does the fact that the subject is not in other respects 
'human or human-like' preclude it from being a Senser? The highlighted verbs in sentences such as these (all from our corpus) illustrate the issue:

(1) In a preference test prior to training, the horse chose the smaller of the two circles

(2) Lizards, snakes, and turtles select environmental temperatures where the detection and capture of prey, reproduction, and digestive processes are most efficient

(3) Planktivorous fish preferred large-bodied over small-bodied zooplankton as food source

(4) The tide had turned and the seal decided to return to the water, quite happily and without any pressure from us

(5) What these larvae want is a lift, a ride, and they want it so badly that sometimes they'll even try and get it from a human finger.

These sentences illustrate the gradient nature of any putative hierarchy of animacy among non-human species. Readers may find less to object to in the description of a horse 'choosing' one of two objects than of larvae 'badly wanting' a ride. ${ }^{2}$ The first three, taken from academic journal articles, are examples of polysemous, or at least ambiguous, verbs. When scientists report the behaviour of non-human creatures, they are obliged by the conventions governing their publications to avoid "ascribing to nonhuman entities the intention to do something" (Goldbort, 2006: 25; see also Rabinowitz \& Vogel, 2009: 23, Sealey and Pak, under review). In fact, the author of this manual for science writers disapproves of 'prefer' to denote animals' ingestion of one substance rather than another, on the grounds that the researcher can only attest to what the animals consumed, and cannot know for sure whether they 'preferred' it. But to what extent is an internal process of intention entailed in externally observable behaviour? Should 'select', 'prefer' and 'want' in these examples be interpreted metaphorically, and/or as evidence of anthropomorphism? Does 'want' here connote a state of desire (as could be implied by 'badly') or of need? (Compare "these shoes [inanimate] want [= stand in need of] a good polish".) Readers will probably also not be surprised to learn that the examples are taken from different discourse genres: (1), (2) and (3) are from academic journal articles, (4) from a campaigning text and (5) from the commentary to a television broadcast. In short, it is clear that classification 
of verbs within the SFL typology is far from adequate as an indication of degree of animacy in this particular context. Furthermore, it is my contention, as illustrated by these examples and in accordance with the claims by Dahl (2008) and Hopper and Thompson (1994) cited above, that variations in discourse types and communicative purpose lead to variations in how the same kind of animal is represented in language. To explore this further, I present several approaches to analysis.

Analysis 1 provides an overview of the verbs associated with numerous animals in just one genre of writing, namely our sub-corpus (approximately 6 million words) of articles published in journals concerned with biology, veterinary and environmental science etc. Here, the verbs associated with the full range of animal naming terms (identified by a tagging process explained in Sealey and Pak, forthcoming) were identified and classified semantically, illustrating the degrees of animacy afforded to animals as they appear in this kind of scientific writing. In light of limitations of space, this analysis focuses primarily on the passive constructions that are (predictably) particularly frequent in this genre. Analysis 2 is a more fine-grained investigation that compares and contrasts the verbs associated with a small number of different animals chosen as 'case studies', while Analysis 3 contrasts how just one of these 'case study' animals is depicted in different discourse genres, by comparing findings across different sub-corpora.

Before proceeding, it is necessary to note some of the challenges associated with these kinds of analysis. As explained elsewhere (Sealey and Pak, forthcoming), our corpus is relatively small in relation to the wide range (over 2000) of animal naming terms used to compile it. This means that many of the figures returned are also quite small, and so cannot be considered statistically significant. Therefore it is often appropriate to look closely at the results generated by corpus tools; this is quite practical with only small numbers of concordance lines to examine. Furthermore, the automated tagging and parsing tools available are considerably less than $100 \%$ accurate. While this is a common challenge for corpus analysis, the errors in this particular data set are revealing in themselves, highlighting some of the peculiarities in the ways animals are represented in different kinds of discourse. 


\section{Analysis 1: Subject animals in scientific journal articles}

This part of the study used AntConc (Anthony, 2014) and a search based on the string \{animal-naming-term + verb\} in the Journals sub-corpus (which is tagged both for animal naming terms and Part of Speech (POS)). Although this string does not retrieve all the relevant data, because of intervening adverbs, pronominal substitutions etc., the search nevertheless generates some interesting findings. The most frequent verb immediately following an animal naming term in the Journals sub-corpus is were (8416 occurrences), of which the great majority (6047) are in passive constructions, where the entities referred to all feature as the 'patients' of processes done to them. A wide range of verbs (551 different verb types) occurs in these passive constructions, where an animal naming term immediately precedes the string \{were + past participle\}, but of these 203 occur only once and another 83 only twice. Table 1 shows the most frequent 34 verb types, which all occur 30 times or more, grouped semantically. The verbs given (ranked $13^{\text {th }}$ ) and allowed $\left(22^{\text {nd }}\right)$, which have multiple meanings, are not included in this table; instead some illustrative concordance lines are provided below.

\begin{tabular}{|c|c|c|c|}
\hline Type of process & Verb & Frequency & Rank by frequency \\
\hline \multirow[t]{3}{*}{ sustain } & fed & 323 & 1 \\
\hline & offered & 49 & $28=$ \\
\hline & maintained & 102 & 10 \\
\hline \multirow[t]{10}{*}{ situate } & housed & 220 & 2 \\
\hline & kept & 187 & 4 \\
\hline & collected & 179 & 5 \\
\hline & placed & 129 & 8 \\
\hline & found & 134 & 7 \\
\hline & removed & 71 & 20 \\
\hline & transferred & 45 & $31=$ \\
\hline & obtained & 82 & 16 \\
\hline & divided & 67 & 21 \\
\hline & selected & 54 & 25 \\
\hline \multirow[t]{3}{*}{ survey } & used & 203 & 3 \\
\hline & observed & 150 & 6 \\
\hline & weighed & 125 & 9 \\
\hline
\end{tabular}




\begin{tabular}{|l|l|r|r|}
\hline & tested & 78 & 16 \\
\hline & sampled & 62 & 23 \\
\hline & examined & 58 & 24 \\
\hline & identified & 51 & $26=$ \\
\hline & recorded & 49 & $28=$ \\
\hline intervene & monitored & 40 & 34 \\
\hline & exposed & 100 & 11 \\
\hline & treated & 97 & 12 \\
\hline & anesthetized (variant spellings) & 87 & 18 \\
\hline & injected & 73 & $26=$ \\
\hline & subjected & 51 & 30 \\
\hline & infected & 47 & $31=$ \\
\hline kill & challenged & 75 & 14 \\
\hline & sacrificed & 91 & 18 \\
\hline & killed & 75 & \\
\hline
\end{tabular}

Table 1. The most frequent verbs in the passive clause construction \{animal-naming-term + were + past participle $\}$

The entities and experiences that animals 'were given' and 'were allowed' include:

a) sustenance

(6) animals were given a $100 \mathrm{~g}$ mixed preload of ground barley

(7) mice were allowed access to food and water ad libitum

(8) foxes were given approximately half of their daily food provision

(9) ticks were allowed to feed on healthy calves

b) biochemical interventions

(10) rats were given pioglitazone (10 mg/kg, p.o., daily) for 4 weeks

(11) clouded leopards were given ketamine hydrochloride $(11.0 \mathrm{mg} / \mathrm{kg})$ intramuscularly

(12) piglets were given $2 \mathrm{ml}$ of ferrodextran

(13) rats were given thyrotropin releasing hormone

c) time

(14) Horses were allowed 21-day adaptation periods 
(15) pigs were given time to explore the new location

(16) ewes were given seven days to get used to the experimental conditions

d) behavioural experiences

(17) Mice were given two training sessions

(18) dogs were given the task of determining the correct direction

(19) hatchlings were allowed to crawl on the sand in the hatchery under open conditions

(20) calves were allowed to stay with the cow

(21) sheep were given the choice between different flooring materials

(22) sows were allowed to mix with other sows

To complement these findings, some of the other most frequent verbs of which animal naming terms are the subject were identified. This analysis revealed that, even in clauses that are in the active voice, many of the frequent verbs denote processes in which the animals' role is relatively passive. For example, it is reported that animals 'accepted', 'ate', 'consumed' and 'received' what was given to them. As research subjects, they 'experienced' and 'underwent' (e.g. 'examination', 'tests') and 'demonstrated', 'displayed', 'presented', 'revealed' and 'showed' things of interest to the scientists. Animals 'excreted' and 'shed' (e.g. 'virus', 'eggs'). As (parts of) their bodies changed, they 'became', 'decreased', 'developed', 'formed', 'gained', 'grew', 'increased', 'reached' (e.g. a 'stage' or 'target', 'puberty'), 'weighed' and 'averaged'. Other verbs in the active voice include 'remained', 'survived' and 'died'.

The data analysed here includes accounts of the experiences of a heterogeneous collection of animals. Overall, the analysis illustrates how these animals' experiences are all heavily managed by the people researching them. As I have noted elsewhere (Sealey and Pak, under review), any potential differences in the characteristics of types of animal are often seen as a hindrance to research, and critics suggest that laboratory animals, selectively bred and standardised as generic 'models' of their kind (Birke, 2012), "have moved from being biological creatures to objects or tools for human use" (DeMello, 2012: 182). With some exceptions, then, it is animals' passivity, rather than their animacy, that is highlighted by the language in these 
science journal articles. The fact that this finding is unsurprising may be seen in the light of contemporary questioning of laboratory practices, and specifically the ways in which these are designed so as to preclude the possibility of animals demonstrating their own concerns or interests, as opposed to those of the humans researching them (Despret, 2016: 91).

\section{Analysis 2: Animals compared across the whole corpus}

With over 2000 animal naming terms in our heterogeneous corpus, only a small subset occur often enough, across a wide enough range of genres, to reveal linguistic patterns. From these, a selection was made of a manageable number to compare and contrast in respect of the patterns in which they are found. The main criterion for selection was frequency in the corpus, both overall and in the sub-corpora of different discourse types (see Sealey and Pak, forthcoming). A second criterion was variety of biological and cultural types, so that the case study animals would represent a range for comparison. In light of these criteria, the animal naming terms selected were $\operatorname{dog}(s), \operatorname{cow}(s)$, fish, $\operatorname{bird}(s)$ and bee(s). It is immediately apparent that these items are not equivalent kinds of designation, although they are all relatively familiar to most people. Predictably, there are more occurrences in the corpus of superordinates, such as 'bird(s)' (4446) than, for example, 'pigeon(s) (267) or 'magpie(s)' (35).

Taxonomically, 'dogs' and 'cows' are both terrestrial mammals, the former belonging to the family of 'caniform' carnivores and the latter ruminant herbivores, but although both subdivide into different 'breeds' there is more variation in the kinds of animal classified as dogs than as cows. 'Bees' are classified as insect pollinators of the order Hymenoptera, suborder Apocrita (Tudge, 2000: 305), whereas there is little agreement on the definition of 'fish' (Dupré, 1999), beyond the colloquial designation of "any vertebrate that is basically streamlined and is basically a swimmer, propels itself primarily by undulations of the body, and breathes by gills" (Dupré 1999: 348). The focus of this investigation, however, is what kinds of behaviour each animal is associated with in this corpus of contemporary British English, and corpus analytic tools were used to make some initial comparisons.

For this I used the 'word sketch' and 'sketch-diff' functions in Sketch Engine (Kilgarriff \& Lexical Computing). 'Word sketches' are summaries of a word's 
grammatical and collocational behaviour, showing the word's collocates categorised by grammatical relations, including, as is the focus here, verbs of which the animal naming term serves as subject. ${ }^{3}$ The 'sketch-diff' function compares two word sketches, in this case those for each of the 'case study' animal naming terms as compared with each of the others, with specific attention to the verbs of which each is identified as subject.

As previously noted, some of the numbers involved are quite small, so that even log dice scores of 7 or above may derive from limited numbers of occurrences; for this reason, examples of the words in context are provided with the discussion. In addition, many highly frequent verbs, including non-lexical be, have and do are uninformative without further investigation. As mentioned above, there is quite a high proportion of errors in the automatic parsing, and although this causes some problems, some of the errors provide evidence of the anthropocentricity of the texts on which automatic parsers are trained. For example, the following were parsed as though the animal naming term was the subject of the verb:

(23) proportion of cows observed self-grooming

(24) the cows milked three times per day

Another example of this mis-parsing is where SketchEngine identifies 12 occurrences of 'farm' as a verb of which 'fish' is the subject, as in a sentence beginning, 'Considering the fish farms separately ...'. These 12 instances are a small proportion of the 161 occurrences of the string 'fish farm(s)', which is itself only one example of the pattern \{animal-naming-term + farm $(s)\}$. Others include: 'pig farm', 'sheep farm', 'shrimp farm' and 'shellfish farm'. There are also 51 occurrences of 'fur farm', where the animal product, rather than the animal itself, is the modifier, and 'factory farm', where the modifier has a different semantic function. This is also the case with 'family farm' (31 occurrences), where we readily infer that the modifier denotes an organizational arrangement and not the product of the farming enterprise. Automatic parsers, however, lack the world knowledge that enables the human reader to process these distinctions without pausing to reflect on them. 
Bearing in mind these caveats, the 'subject of' function in sketch-diff calculations should highlight those verbs of which the named animals are subjects. As in Analysis 1 above, many of the processes shared between these five animal naming terms denote basic existence: e.g. live, become, experience, survive, consume, eat - and also die. The relations between animals and human perspectives are evident again in verbs denoting that they both provide information: e.g. show, exhibit, present and are used for human purposes: e.g. produce:

(25) dairy cows produce both milk and calves (journals)

(26) efficient cows produce more milk from the same energy intake (journals)

(27) Each one [egg] rolls down on to another conveyor belt as soon as the bird produces it (news)

Cognitive linguists have pointed out that the location of the human body in space provides the default stance for linguistic denotations of perspective and motion (Levinson, 2003; Talmy, 2000), which perhaps makes alternative means of locomotion worthy of comment. Some of the verbs identified by the process used here recall children's early reading books, from which they learn that fish 'swim' and birds 'fly', e.g:

(28) I like watching birds flying overhead (Mass Observation)

(29) You see all these big fish swimming about and it's like an aquarium (broadcast)

(30) Reef fish swim out to gorge themselves (broadcast)

Likewise, the sounds made by different kinds of animals are highlighted by this process, but interestingly these are predominantly choices made by transcribers of the qualitative interviews we conducted for the project and of television broadcasts. Thus, dogs 'bark' and birds 'chirp' when the sounds these animals make are noted for viewers of subtitles and readers of the transcripts.

(31) (dog barking) We know what you sound like thank you (interview with dog owner) 
(32) A world lost in the vastness of the Pacific (birds chirping) home to the strangest life imaginable (broadcast)

The impression produced by this analysis is consistent with the summary presented above, of nonhumans existing fairly passively in a human-centred environment, except insofar as they make their presence felt by the sounds they produce and their contrasting modes of locomotion. These animals are animate, but in a relatively undifferentiated way, depicted from a perspective that emphasizes their utility to humans as sources of produce and information. In the third analysis I delve a little deeper by contrasting different modes of discourse in respect of just one of these 'case study' animal types.

\section{Analysis 3: Contrasting representations of dogs}

The salience of dogs in contemporary British discourse about animals is evident from the fact that $\operatorname{dog}(s)$ was one of the most frequent animal naming terms across all discourse types in our corpus. So as to be able to identify robust linguistic patterns, we further supplemented our corpus data about this animal in two ways. We were fortunate to be given access to a set of interviews conducted by one of our consultants with people who live with dogs as companions, which supplements our other elicited data (i.e. written submissions from the Mass Observation Project directive on 'Animals and Humans'; interviews with professional communicators about animals; and focus groups with a range of different participants). We also collected, in addition to the news sub-corpus derived from our full list of animal name search terms, a further corpus of news texts (just over 4,500,000 words) featuring our five case study animals, including dogs.

As before, the analysis began by identifying the verbs of which the animal naming term was the subject - in this case $\operatorname{dog}(s)$. The datasets used were (a) the legislation sub-corpus, (b) the supplementary news corpus and (c) the elicited data corpus. For this analysis, descriptors for $\operatorname{dog}(s)$ were also identified. Some of the patterns found are inevitably the product of the discourse features of the respective genres. For example, legal discourse is "extremely conservative" and seeks precision and a restriction on potential interpretations (Bhatia, Langton, \& Lung, 2004: 206). News is 
characterized by recognized 'values', including negativity (Bednarek, 2006; Bell, 1991), while our elicited data involved respondents replying to questions and prompts that were phrased in particular ways, which may have influenced their own formulations.

Dogs have a liminal legal status, "somewhere in between a person and a piece of personal property" (Garner, 2002: 85n, citing a legal judgement). The word sketch for $\operatorname{dog}(s)$ in our legislation sub-corpus shows them as subjects of very few active verbs, with one instance each, for example, of 'defecate' and 'kill' - both prohibited actions, in specified circumstances, for which the owner would be held responsible. Other offences for which owners would be liable are mitigated by exceptions when a human is 'in charge of' a dog 'being used' in various ways:

- for [a blind] person's guidance

- for the driving or tending of sheep or cattle

- on official duties by a member of Her Majesty 's Armed Forces or Her Majesty's Customs

- in emergency rescue work.

The impression of dogs as (living) tools is supported by phrases such as "the manner in which the dog is used", whereas the animals' inherent agency is more evident in the following examples, which allude to their potential to act in accordance with different interests from those of the people deemed responsible for them:

(33) a dog is out of control if (a) it is not being kept under control effectively and consistently

(34) in particular the dog is brought under sufficiently close control to ensure that it does not prevent or obstruct achievement.

A kind of personhood, in the sense of accountability, is connoted by the word choice in the following examples too, where a word or phrase denoting a human agent could readily be substituted for 'the dog' (though not in the final, passive clause of (36)):

(35) the dog is subject to the prohibition in section 1 (3) above

(36) the court shall order that unless the dog is exempted from that prohibition within the requisite period the dog shall be destroyed 
When the law is broken, news is often made, as it is by unexpected events and when human beings or their property are hurt or damaged. Many of the news texts that feature dogs include them as the subjects of the verb attack. In this sub-corpus, where incidents are often reported in quoted first-person accounts, dogs may feature as active attackers, e.g.:

(37) Initially one of the dogs attacked me, then as it was latched onto my arm the other two dogs started to attack my dog.

As in that example, the 'victims' of the attack may be not only humans but also other animals:

(38) This dog has violently attacked numerous cattle and horses since its escape.

(39) I have experience of an aggressive little dog attacking a harmless big one.

However, when the victims are human, it is they who are likely to be foregrounded, sometimes by presentation of the surrounding circumstances in an extended narrative, as in these examples:

(40) it was at this point one of their dogs attacked the baby

(41) friendly relations deteriorated and reached a nadir this summer when the dog attacked the Malias' son

(42) shouted at her to "keep pedalling" - but the dogs attacked and dragged her off the bike

(43) The girl was picking flowers near Hillcross Avenue at about 3pm on Saturday when the dog attacked

The humans affected are also foregrounded through the use of passive constructions:

(44) Nine postmen and women were attacked by dogs every day last year

(45) A 12-year-old girl was attacked by a dog as she played with her sister in a south London park

(46) Jade Anderson was attacked by four dogs while alone in a friend's house

(47) He was attacked by two dogs, and it carried on for 20 minutes. 
And the negativity of the news story is heightened by details of the victims' injuries in these mostly passive constructions:

(48) A FOUR-year-old girl has been left scarred for life after being attacked by a Japanese Akita dog

(49) Seventy-nine-year-old Clifford Clarke died after being attacked by a dog in the garden of his home

(50) Nearly 3,800 people in England needed emergency hospital treatment after being attacked by dogs last year

(51) A two-year-old boy has suffered serious facial injuries after being attacked by two dogs in Wiltshire

(52) Four-year-old Lexi Branson suffered horrific injuries after the dog attacked her at their home

(53) In September a woman had her left arm almost mauled off after her pet Canary dog attacked her

A 'Canary dog' is a cross between mastiff and bulldog, and this story continues with a quote describing it as "a fearless, powerful and able fighting machine". This is consistent with the idea of the dog as a tool, with the potential to be 'out of (human) control'. The collocation 'dangerous dog(s)' occurs 95 times in this news corpus, and fear of this phenomenon has been identified as a 'moral panic' (Cameron, 1995). In this discourse, the dogs are perceived as 'tools' used by humans for criminal ends, but are themselves punished, by being 'destroyed', for having 'the wrong imputed characteristics" (Hallsworth, 2011: 391). These are the villains of the dog news stories.

However, another frequent modifier of $\operatorname{dog}(s)$ in this corpus is 'guide' (84 occurrences), and here the picture is different. As illustrated in the following examples, these dogs are depicted as having a positive role in human experience, 'bringing joy', 'making a positive difference' and being 'essential' for some particular human needs.

(54) Guide dogs are essential for the mobility, independence and dignity of blind men and women 
(55) HEARTLESS thieves stole a guide dog which brought joy to a woman who lost her sight ten years ago

(56) her aunt became acutely aware of what an incredibly positive difference a guide dog can make to the lives of those with sight loss

They are also depicted as exceptional, in comparison to other dogs, and of high monetary value:

(57) Our policy is to allow guide dogs only into our restaurants

(58) In Britain there are about 5,000 working guide dogs, which cost the Guide Dog Association $£ 35,000$ in food, vets' bills and sundries to maintain

(59) The thorough and specialised training that transforms a new-born puppy into a confident guide dog takes about 20 months

News stories also illustrate the idea of the dog as property from which people can profit, whether legitimately or not:

(60) This, they say, allows thieves to identify dogs worth stealing

(61) Young pedigree dogs can fetch between $£ 400$ and $£ 500$, but older dogs are worth a lot less

(62) A good dog can earn a man hundreds of thousands. Star dogs are worth between $£ 30,000$ and $£ 50,000$

However, the dog as person, as well as property, is represented in an account of a theft:

(63) This is not about how much the two dogs are worth in monetary terms, but about having two much-loved members of their family snatched

It is as 'kin' that the collector of two components of the third data-set used in this analysis explores the role of dogs in human society $£$ Charles, 2014 \#2581\$, and these texts illustrate some different linguistic features from those found in laws and in news stories. The respondents to the Mass Observation directive and those interviewed about the dogs they lived with refer to dogs' value to humans, as in these examples, which are just two of the several instances of dogs being described as 'loyal': 
(64) dogs are very loyal easy to train and there seem to be many instances of them saving people's lives

(65) dogs are very loyal and they can be taught how to do tasks which help their master

Other examples, from a range of respondents in the elicited data include:

(66) a dog is utterly devoted to you and is completely loyal

(67) A dog is very loyal, I do not know of any other animal that would come near to it

While 'loyal' connotes the relationship between dog and human, it affords the former a greater degree of agency than is evident in the tool/machine image seen in the previous discourses. Other descriptors include 'dependable', 'loving', 'giving', 'lovely', 'friendly', 'cheeky', 'reliable', 'special' and 'intelligent':

(68) dogs are very loyal and giving

(69) dogs are by nature very loyal and dependable they come when called and generally are very loving

(70) you couldn't get any more loving than these dogs are

(71) he's a very loving, friendly dog

(72) they've all been loving and cheeky, so. . . He's special because he's ours

(73) I believe that there is a lot of truth in a dog being a person's best friend. They are much more reliable and loving than most humans.

(74) we had Dalmatians, and they're lovely dogs ... they 're very intelligent, but no I think spaniels are more loving

This data-set also includes references to a wider range of abilities, as in the following examples, where $\operatorname{dog}(s)$ is the subject of the cognitive verbs know and understand, as well as the communicative answer and also work:

(75) these dogs know the difference between when they are working and when they're as they are now

(76) I'll talk to him sometimes and he will answer you and he knows what words are

(77) my brother says that/that his dog understands everything he says 
(78) Oh I think they understand a hell of a lot, yes, yes

This final analysis demonstrates some of the ways in which contrasting discursive contexts and communicative purposes lead to different ways of representing the same kind of animal. There are probably few surprises here: these kinds of texts are fairly familiar to general audiences, and dogs are animals that are widely integrated into many human societies. However, I suggest that these various linguistic patterns represent examples of how this particular kind of animal, the dog, can simultaneously occupy different places in a notional hierarchy of characteristics: mechanistic brute, useful tool, loyal companion, loving family member and intelligent agent - depending on the stance of the human producing the discourse.

\section{Conclusion}

As discussed above, some definitions of animacy rest on the idea of 'entities' having 'inherent qualities and abilities' (Folli \& Harley, 2008). However, the linguistic examples presented in these three short corpus-assisted analyses present some challenges to this concept.

One issue of course, which philosophers have grappled with for centuries, is the relationship between any real-world 'entity' and its representation in the language. There are many ways of naming living organisms, but in human language these are all likely to be influenced, if not determined, by both human perceptions and human interests. Our own experience of ourselves as individual entities, our modes of sensory perception, and the conventions by which we name ourselves and other entities, all encourage conceptions of animals as members of contrasting species, each with fixed characteristics. The linguistic resources available to us are much less accommodating of the dynamism, fluidity and contingency that are invoked by the concept of organisms and species as 'assemblages' (DeLanda, 2016: 149; Dupré, 2012: 203; Hird, 2009: 67).

A second issue relates to interactions, not only between different aspects of the linguistic system, but also between discourse and entities, both organic and inorganic. The analyses presented here illustrate the ways in which animals are depicted as 
participating in various processes, and the relations between those depictions and the concerns of the producers of the texts where they are found. Thus researchers observing animals in the laboratory will report them as 'exhibiting' or 'showing' - or not - the behaviours that are the objects of their experiments. Participants in agricultural and food enterprises emphasise what animals produce. Journalists with an interest in 'newsworthy' topics construct stories about animals as 'villains' and 'heroes', while individuals asked to reflect on their first-hand experiences with companion animals represent them with a much greater degree of personhood. The analyses of our corpus suggest that the kind of animal accorded the widest range of characteristics of animacy there is the dog, which is portrayed as possessing differential characteristics, including emotional, social and cognitive capacities.

Necessarily absent from all of these discourses are direct representations from any animal's own perspective. Perceptual capacities are encoded in human languages in accordance with human senses, which conventionally include seeing and hearing (the more privileged senses), as well as touching, tasting and smelling. Many animals have these senses to much greater extents than humans, making it almost certain that their perceptual abilities are greater too - e.g. the visual acuity of birds of prey (e.g. Ackerman, 2016), the olfactory acuity of dogs. Other species also have sensory abilities that are not readily encoded in language, such as those of navigation by magnetic field, detection of prey by electrical charge and so on (e.g. Burghardt, 1991). Characteristics of animals as members of larger groups, such as bees and ants in colonies, contrast with the individual notions of identity fostered by many aspects of the encoding of human experience in language. And many of the qualities that lead to descriptions of dogs as having human-like characteristics are now being recognised in other species. A summary of these kinds of capacities in pigs, though with reference to similar capacities in a wide range of other species, is presented in Marino and Colvin (2015). This survey covers nonsocial cognition (i.e. object discrimination, time perception, spatial learning, novelty seeking, inquisitiveness and play), social cognition (i.e. discriminating conspecifics and others, and perspective-taking) selfawareness, emotion, and personality. Contemporary research about animals leading non-terrestrial lives, including cetaceans (e.g. Jensen \& Tyack, 2013) and octopuses (e.g. Godfrey-Smith, 2013) is also widening human understanding of the perceptual, 
cognitive, behavioural, emotional and social lives of aquatic species. It seems likely, then, that human language, or at least the contemporary British English that comprises the data analysed here, has some distance to go before it can accommodate the many ways in which animals' animacy may potentially be understood.

\begin{tabular}{|c|c|c|}
\hline \multicolumn{3}{|l|}{ Appendix } \\
\hline Sub-Corpus & $\begin{array}{l}\text { No of } \\
\text { Files }\end{array}$ & $\begin{array}{l}\text { No. of } \\
\text { Tokens }\end{array}$ \\
\hline Broadcasts & 83 & 614378 \\
\hline Campaign literature & 470 & 306680 \\
\hline Legislation & 843 & 627127 \\
\hline Food websites & 258 & 87118 \\
\hline Journals & 1609 & 5698531 \\
\hline News & 1023 & 466340 \\
\hline $\begin{array}{l}\text { Contributions to the Mass Observation } \\
\text { Project }\end{array}$ & 103 & 174938 \\
\hline Focus groups & 19 & 229059 \\
\hline Interviews with text producers & 17 & 157664 \\
\hline Interviews with guardians/keepers of dogs & 19 & 309719 \\
\hline Total & 4444 & 8671554 \\
\hline
\end{tabular}

Table 2. The composition of the main corpus

\section{References}

Ackerman, J. (2016). The Genius of Birds (Kindle ed.). London: Corsair. Anthony, L. (2014). AntConc (Version 3.4.3). Tokyo, Japan. Retrieved from http://www.antlab.sci.waseda.ac.jp/

Arluke, A., \& Sanders, C. R. (1996). The sociozoologic scale. In A. Arluke \& C. R. Sanders (Eds.), Regarding Animals (pp. 167-186). Philadelphia, PA: Temple University Press.

Atran, S. (1999). The universal primacy of generic species in folkbiological taxonomy: implications for human biological, cultural and scientific evolution. In R. A. Wilson (Ed.), Species: new interdisciplinary essays (pp. 231 - 261). Cambridge, Mass.: Massachusetts Institute of Technology.

Bednarek, M. (2006). Evaluation in Media Discourse: analysis of a newspaper corpus. London: A\&C Black.

Bell, A. (1991). The Language of News Media. Oxford: Blackwell.

Bennett, J. (2010). Vibrant Matter: a political ecology of things: Duke University Press.

Bhatia, V. K., Langton, N. M., \& Lung, J. (2004). Legal discourse: opportunities and threats for corpus linguistics. In U. Connor \& T. A. Upton (Eds.), Discourse 
in the professions: Perspectives from corpus linguistics (Vol. 16, pp. 203231). Amsterdam: John Benjamins

Birke, L. (2012). Animal bodies in the production of scientific knowledge: modelling medicine. Body \& Society, 18(3-4), 156-178. doi:10.1177/1357034X12446379

Burghardt, G. M. (1991). Cognitive ethology and critical anthropomorphism: a snake with two heads and hognose snakes that play dead. In C. A. Ristau (Ed.), Cognitive ethology: the minds of other animals. Essays in honor of Donald R. Griffin (pp. 53-90). Hillsdale, NJ, US: Lawrence Erlbaum Associates.

Cameron, D. (1995). Verbal Hygiene. London: Routledge.

Clutton-Brock, J. (1995). Aristotle, the scale of nature, and modern attitudes to animals. Social Research, 421-440.

Comrie, B. (1989). Language Universals and Linguistic Typology: syntax and morphology: University of Chicago press.

Coole, D., \& Frost, S. (2010a). Introducing the new materialisms. In D. Coole \& S. Frost (Eds.), New materialisms: Ontology, agency, and politics (pp. 1-43).

Coole, D., \& Frost, S. (Eds.). (2010b). New Materialisms: ontology, agency, and politics.

Croft, W. (1991). Syntactic Categories and Grammatical Relations: the cognitive organization of information. Chicago: University of Chicago Press.

Dahl, O. (2000). Animacy and the notion of semantic gender. In B. Unterbeck (Ed.), Gender in Grammar and Cognition (Vol. 124, pp. 99-116).

Dahl, 0. (2008). Animacy and egophoricity: grammar, ontology and phylogeny. Lingua, 118(2), 141-150.

Dahl, O., \& Fraurud, K. (1996). Animacy in grammar and discourse. In T. Fretheim \& J. K. Gundel (Eds.), Reference and Referent Accessibility (pp. 47 - 64). Amsterdam: John Benjamins.

De Swart, P., Lamers, M., \& Lestrade, S. (2008). Animacy, argument structure, and argument encoding. Lingua, 118(2), 131-140.

DeLanda, M. (2016). Assemblage Theory. Edinburgh: Edinburgh University Press.

Deleuze, G., \& Guattari, F. (1988). A Thousand Plateaus: capitalism and schizophrenia. London: Bloomsbury

DeMello, M. (2012). Animals and Society: an introduction to human-animal studies. New York: Columbia University Press.

Despret, V. (2016). What Would Animals Say if we Asked the Right Questions? (B. Buchanan, Trans.). Minneapolis: University of Minnesota Press.

Dupré, J. (1999). Are whales fish? In D. L. Medin \& S. Atran (Eds.), Folkbiology (pp. 461-476). Cambridge, Mass.: MIT Press.

Dupré, J. (2012). Processes of Life. Oxford: Oxford University Press.

Dupré, J., \& O'Malley, M. A. (2007). Metagenomics and biological ontology. Studies in History and Philosophy of Biological and Biomedical Sciences, 38, 834846.

Enger, H.-O., \& Nesset, T. (2011). Constraints on diachronic development: the Animacy Hierarchy and the Relevance Constraint. STUF-Language Typology and Universals Sprachtypologie und Universalienforschung, 64(3), 193-212. 
Folli, R., \& Harley, H. (2008). Teleology and animacy in external arguments. Lingua: Animacy, Argument Structure, and Argument Encoding, 118(2), $190-192102$.

Garner, R. (2002). Political ideology and the legal status of animals. Animal Law, $8,77-91$.

Gilquin, G., \& Jacobs, G. M. (2006). Elephants who marry mice are very unusual: the use of the relative pronoun who with nonhuman animals. Society \& Animals, 14(1), 79 - 105.

Godfrey-Smith, P. (2013). Cephalopods and the evolution of the mind. Pacific Conservation Biology, 19(1), 4-9.

Goldbort, R. (2006). Writing for Science: Yale university press.

Gupta, A. F. (2006). Foxes, hounds, and horses: who or which? Society \& Animals, 14(1), 107 - 128.

Halliday, M. A. K. ([1990] 2001). New ways of meaning: the challenge to applied linguistics. In A. Fill \& P. Mühlhäusler (Eds.), The Ecolinguistics Reader (pp. 175 - 202). London \& New York: Continuum.

Halliday, M. A. K., \& Matthiessen, C. M. I. M. (2004). An Introduction to Functional Grammar (3rd ed.). London: Arnold.

Hallsworth, S. (2011). Then they came for the dogs! Crime, law and social change, 55(5), 391-403.

Herzog, H. (2010). Some We Love, Some We hate, Some We Eat: why it's so hard to think straight about animals. New York: Harper Perennial.

Hird, M. J. (2009). The Origins of Sociable Life: evolution after science studies. New York: Palgrave Macmillan.

Hopper, P. J., \& Thompson, S. A. (1994). Language universals, discourse pragmatics, and semantics. Language Sciences, 15(4), 357-376.

Jensen, F. H., \& Tyack, P. L. (2013). Studying acoustic communication in pilot whale social groups. The Journal of the Acoustical Society of America, 134(5).

Kilgarriff, A., \& Lexical Computing. Sketch Engine: http://www.sketchengine.co.uk. Retrieved from http://www.sketchengine.co.uk

Langacker, R. W. (1991). Foundations of Cognitive Grammar (Vol. II Descriptive Application). Stanford, CA: Stanford University Press.

Leheckovd, H. (2000). Use and misuse of gender in Czech. In B. Unterbeck (Ed.), Gender in Grammar and Cognition (Vol. 124, pp. 749 - 770).

Levinson, S. C. (2003). Space in Language and Cognition: Explorations in cognitive diversity (Vol. 5). Cambridge: Cambridge University Press.

Malchukov, A. L. (2008). Animacy and asymmetries in differential case marking. Lingua, 118(2), 203 - 221.

Marino, L., \& Colvin, C. M. (2015). Thinking pigs: a comparative review of cognition, emotion, and personality in sus domesticus. International Journal of Comparative Psychology, 28.

Nussbaum, M. (2007). The moral status of animals. In L. Kalof \& A. Fitzgerald (Eds.), The Animals Reader (pp. 30 - 36). Oxford \& New York: Berg.

Pavlinov, I. Y. (2013). The species problem, why again. The Species ProblemOngoing Issues, 3-37. 
Rabinowitz, H., \& Vogel, S. (Eds.). (2009). The Manual of Scientific Style: a guide for authors, editors, and researchers: Academic Press.

Santamaria, S. L., Fallon, M., Green, J. M., Schulz, S., \& Wilcke, J. R. (2012). Developing the animals in context ontology. Paper presented at the ICBO.

Sealey, A., \& Oakley, L. (2013). Anthropomorphic grammar? Some linguistic patterns in the wildlife documentary series Life. Text \& Talk, 33(3), 399420.

Sealey, A., \& Pak, C. (forthcoming in 2018). First catch your corpus: methodological challenges in constructing a thematic corpus. Corpora, $13(2)$.

Stibbe, A. (2006). Deep ecology and language: the curtailed journey of the Atlantic salmon. Society \& Animals, 14(1), 61 - 77.

Talmy, L. (2000). Toward a Cognitive Semantics (Vol. 2). Cambridge, Mass.: MIT press.

Thomas, K. (1983). Man and the Natural World: changing attitudes in England 1500-1800: Penguin UK.

Tudge, C. (2000). The Variety of Life: a survey and a celebration of all the creatures that have ever lived. Oxford: Oxford University Press.

Yamamoto, M. (1999). Animacy and Reference: a cognitive approach to corpus linguistics. Amsterdam: John Benjamins.

Zaenen, A., Carletta, J., Garretson, G., Bresnan, J., Koontz-Garboden, A., Nikitina, T., ... Wasow, T. (2004). Animacy encoding in English: why and how. Paper presented at the Proceedings of the 2004 ACL workshop on discourse annotation.

\footnotetext{
${ }^{1}$ Acknowledgements: This research project, 'People', 'products', 'pests' and 'pets': the discursive representation of animals, was funded by the Leverhulme Trust (RPG 2013-063). Other members of the research team include Chris Pak, who processed some of the data for these analyses, Clyde Ancarno, Guy Cook, Anda Drasovean, and Emma McClaughlin, although they are not responsible for the contents of this paper. I am also grateful to two anonymous reviewers for comments on an earlier version.

${ }^{2}$ See Herzog (2010: 206-207) for an illustration of the inverse hierarchy. He found it 'easy' to immerse worms and crickets into boiling water for a laboratory experiment, harder to kill a lizard in the same way, and impossible to do this to a mouse. He ponders whether his increasing difficulties were due to each animal's 'size, phylogenetic status' or degree of 'cuteness'.

${ }^{3}$ For an explanation of the statistics used in these calculations, see https://www.sketchengine.co.uk/documentation/statistics-used-in-sketch-engine/
} 